SISTEMA
ELETRONICO
DE REVISTAS
SER I UfPR

\title{
Escalas da injustiça hídrica: estudo de caso em Ilhabela - Litoral Norte de São Paulo
}

\section{Scales of water injustice: a case study in Ilhabela - North Coast of São Paulo}

\author{
Natalia Dias TADEU ${ }^{1,2}$ *, Paulo Antônio Almeida SINISGALLI ${ }^{1}$ \\ ${ }^{1}$ Programa de Pós-Graduação em Ciência Ambiental, Universidade de São Paulo (USP), São Paulo, SP, Brasil. \\ ${ }^{2}$ Facultad de Ciencias Sociales, Universidad de la Republica Uruguay (Udelar), Montevideo, Uruguay \\ *E-mail de contato: nataliadiast@gmail.com
}

Artigo recebido em 6 de maio de 2019, versão final aceita em 4 de outubro de 2019.

RESUMO: Este artigo buscou compreender como a estratégia de reescalonamento é empregada para influenciar as relações sociopolíticas e de poder, bem como meio de promoção de determinados interesses que acabam produzindo injustiças hídricas em escala local, tomando como base o estudo de caso em Ilhabela (Litoral Norte - SP). Esta pesquisa se insere no campo da Ecologia Política da Água e emprega conceitos de 'construção de novas configurações de escalares' e territórios hidrossociais. Foi possível verificar que no território hidrossocial local, a injustiça hídrica, que leva ao cerceamento de acesso à água por determinados grupos sociais, não é determinada pela disponibilidade hídrica, mas sim por aspectos sociopolíticos e econômicos, sendo fortemente influenciada pela reorganização da estrutura organizacional e administrativa após a formação de uma região metropolitana.

Palavras-chave: territórios hidrossociais; injustiça hídrica; política escalar.

ABSTRACT: This article sought to understand how the rescaling strategy is used to influence sociopolitical and power relations and means of promoting certain interests that produce water inequities at local scale, starting from the case study in Ilhabela (North Coast - SP/Brazil). This research is in the field of Political Ecology of Water and employs concepts of 'creation of new scalar configurations' and hydrosocial territories. It was possible to verify that in the local hydrosocial territory, the water injustice that leads to the restriction of access to water by certain social groups is not determined by the water availability, but by socio-political and economic aspects, being strongly influenced by the reorganization of the organizational and administrative structure after the formation of a metropolitan region.

Keywords: hydrosocial territories; water injustice; scalar politic. 


\section{Introdução}

O acesso à água é uma questão que não possui relação direta com a disponibilidade hídrica. Essa é uma premissa deste trabalho, que é explorada a partir de um estudo de caso que enfoca a disputa pela água em uma sub bacia hidrográfica, localizada no município de Ilhabela, na qual se observa uma relativa alta disponibilidade hídrica (CBHLN, 2017a). Contudo, parte da população não é atendida pelo serviço oficial de abastecimento de água durante o período de menor precipitação pluviométrica (Cetesb, 2018; CBHLN, 2018).

Parte-se da compreensão de que a "indisponibilidade hídrica", em muitos casos, poderia estar associada mais fortemente à motivações e interesses sociopolíticos e econômicos, produzindo mais uma "escassez político-econômica da água" do que a uma "escassez física" (ou seja, qualitativa e quantitativa) propriamente dita. O termo "disponibilidade político-econômica" é empregado aqui para se referir aos diversos interesses econômicos e políticos, representados por atores que atuam no processo de tomada de decisão da distribuição de água potável, que podem influenciar quem terá acesso à água $\mathrm{e}$ como esse acesso será feito.

Trabalhos como Tadeu et al. (2018) e Alves et al. (2018), realizaram o mapeamento de coalizões multiníveis e analisaram a estrutura do processo de tomada de decisão de conflitos hídricos, envolvendo o setor de saneamento básico no Litoral Norte do Estado de São Paulo. Esses estudos focaram na análise das articulações entre atores e instituições envolvidos nos conflitos na disputa por influenciar a tomada de decisão do setor de saneamento básico.

Esta pesquisa busca ampliar essa compreensão através da análise acerca das disputas entre projetos, valores e ideias opostas para compreender como estes podem influenciar ou modificar as relações que se dão a partir da conformação dos fluxos hídricos. Esta análise é realizada a partir da perspectiva fornecida pela análise de "política escalar" (Hoogesteger et al., 2017). Nesta abordagem, o conceito de territórios hidrossociais (Hoogesteger \& Verzijl, 2015; Hommes et al., 2016; Boelens et al., 2016; Hoogesteger et al., 2016; Hommes \& Boelens, 2017; Swyngedouw \& Boelens, 2018) é central e possibilitará explorar como as escalas são (re)conformadas ou (re)criadas de forma estratégica nos processos de disputas entre os imaginários (objetivos e projetos hidrológicos) de grupos distintos de atores.

Posto isto, este artigo buscou compreender como a estratégia de reescalonamento - ou criação de nova configuração escalar (Swyngedouw, 2004; Hoogesteger \& Verzijl, 2015; Hoogesteger et al., 2017) - é empregada para influenciar as relações sociopolíticas e de poder e como meio de promoção de determinados interesses. A hipótese aqui testada é a de que o processo de reescalonamento, por meio da construção de uma nova configuração escalar, poderia moldar determinadas regras, direitos e estruturas organizacionais que, por sua vez, poderiam (re)alinhar as hierarquias de poder hídrico, associado a múltiplas escalas que produzem injustiças hídricas em escala local, como a do estudo de caso em Ilhabela.

Essa discussão localiza esta pesquisa no campo da ecologia política da água e da busca de ampliação dos diálogos de abordagens interdisciplinares. Inicialmente, se propõe uma delimitação da abordagem dos territórios hidrossociais e dos processos de escalonamento empregados pelos atores, para, em seguida, apresentar e discutir o 
estudo de caso do conflito gerado pela dificuldade de acesso à água em Ilhabela, que envolve atores que atuam em distintas escalas e se articulam em coalizões políticas multiníveis (Massardier et al., 2016; Poupeau et al., 2018; Tadeu et al., 2018). Por fim, se contextualiza e discute o processo de regionalização, aqui apresentados como formas de manipulação das escalas, que acaba por influenciar a questão do acesso à água em escala local.

Para o desenvolvimento desta pesquisa foi realizada uma revisão bibliográfica narrativa (Cook et al., 1997) dos conceitos que embasam a análise deste trabalho, tais como territórios hidrossociais e '(re)construção de novas configurações escalares' (Hoogesteger \& Verzij1, 2015; Boelens et al., 2016; Hoogesteger et al., 2016). A estratégia de reescalonamento (ou criação de nova reconfiguração escalar) como um meio de promoção de determinados interesses (Swyngedouw, 2004) será analisada com base na abordagem de 'política escalar' (Hoogesteger \& Verzijl, 2015; Hoogesteger et al., 2017). Para isso, o estudo de caso que enfoca no conflito socioambiental pelo acesso à água no município de Ilhabela realizou:

1. Entrevistas semiestruturadas com os atores relacionados direta ou indiretamente ao conflito socioambiental pelo acesso à água, ao sul do município de Ilhabela, durante o período de julho de 2015 e outubro de 2016';

2. Levantamento de dados secundários a partir de atas de reuniões do Comitê de Bacias Hidrográficas, do Conselho de
Desenvolvimento da Região Metropolitana do Vale do Paraíba e Litoral Norte, de entrevistas públicas e notícias veiculadas sobre o período do conflito estudado (de 2012 a 2018) e do mapeamento e análise das coalizões multiníveis realizado por Tadeu et al. (2018).

As entrevistas foram realizadas através do método bola de neve (Biernacki \& Waldorf, 1981), iniciando pelos atores previamente identificados por sua participação no Comitê de Bacias Hidrográficas do Litoral Note (CBHLN).

\section{Territórios hidrossociais e escalas da injustiça hídrica}

Para adentrar a discussão acerca das definições conceituais sobre territórios hidrossociais, cabe antes apresentar uma breve definição do que se compreende como território nesta pesquisa. Posto isto, Haesbaert (2004) vai destacar que o território tem relação com o poder, mas não apenas o poder político tradicional (dominação), e sim com o poder no sentido mais simbólico, como o da apropriação. Nessa concepção, o território imerso em relações de dominação/apropriação se desdobra em um "continuum". E, enquanto um continuum, o território precisa ser trabalhando na multiplicidade de suas manifestações, considerando a diversidade de poderes e sujeitos que o constroem (Haesbaert, 2004).

Nesta perspectiva, Raffestin (1993) irá tratar da muldimensionalidade dos poderes que atuam sobre o território. $\mathrm{O}$ autor parte da compreensão de

${ }^{1}$ Foram entrevistados os mesmos atores citados em Tadeu et al. (2018). 
que o poder é inerente a toda relação, e o território resulta das relações assimétricas de poder entre atores. Segundo o autor: "Toda prática espacial, mesmo embrionária, induzida por um sistema de ações ou de comportamentos se traduz por uma "produção territorial" que faz intervir tessitura, nó e rede" (Raffestin, 1993, p. 150). Sendo esses sistemas de tessituras, nós e redes, organizados de forma hierárquica para garantir o controle sobre o que se intenciona distribuir, alocar ou possuir (Raffestin, 1993).

As conceituações de Haesbaert (2004) e Raffestin (1993) permitem compreender que os conceitos de territórios se relacionam com as relações de poder e podem ser compreendidos a partir de uma perspectiva material, social, política, simbólica, dentre outras. Essa compreensão de território possibilita avançar na análise de territórios hidrossociais, entendidos como configurações espaciais de pessoas, instituições, fluxos de água, tecnologia hidráulica e ambiente que giram em torno do controle da água (Hoogesteger et al., 2016).

O conceito de territórios hidrossociais é definido por Boelens et al. (2016) como configurações espaciais de pessoas, fluxos de água, instituições, tecnologia hidráulica e o ambiente biofísico que estão relacionados ao controle sobre a água. Esse conceito é empregado para compreender como ocorrem as disputas entre projetos hidrossociais concorrentes (Hoogesteger \& Verzij1, 2015; Hoogesteger et al., 2016; Boelens et al., 2016). Isto porque, como aponta Boelens et al. (2016), os territórios são historicamente construídos por meio das interrelações entre sociedade, natureza e tecnologia e os seus conteúdos, limites e conexões socionaturais são produzidos pelas práticas sociais, imaginação humana e os sistemas de conhecimento relacionados. Suas projeções e estratégias de construção competem, se alinham e se sobrepõem fortalecendo determinadas reivindicações ou formas de controle sobre a água (Boelens et al., 2016).

Com isso, torna-se possível analisar e compreender como os imaginários contestados e suas materializações ${ }^{2}$ contribuem para a compreensão da diversidade territorial em seu contexto espacial e temporal, caracterizando uma multiplicidade de atores com interesses divergentes e seus projetos hidrossociais (Hommes et al., 2016; Hommes \& Boelens, 2017). A partir da conceituação de territórios hidrossociais, é possível ainda ampliar a compreensão sobre como essas disputas visam consolidar fronteiras, formas de organização socionatural e controle para uma determinada finalidade, associadas à uma escala espacial específica (Hoogesteger $\&$ Verzij1, 2015). E é com base nisso que este artigo visa explorar como os atores articulam estratégias multiescalares para exercer maior controle sobre a água no território.

A noção de imaginários (contestados), central na abordagem dos territórios hidrossociais a partir da abordagem da ecologia política (Boelens et al., 2016), contribui para a descrição sobre como grupos de interesses e alianças entre atores com interesses divergentes interpretam as diversas configurações territoriais atuais e como estas precisam ser reconfiguradas no futuro. No horizonte futuro, estão as aspirações e ideias a respeito de planos hidrotécnicos e sociais, associados a valores, símbolos, nor-

\footnotetext{
${ }^{2}$ Os territórios hidrossociais, que podem ser imaginados, planejados ou materializados, possuem funções, valores e significados que podem ser contestados, tendo em vista que estes definem processos de inclusão e exclusão que afetam diferentes grupos sociais de diversas maneiras (Boelens et al., 2016).
} 
mas, instituições e relações sociais correspondentes (Hommes \& Boelens, 2017).

Outro aspecto relevante, apontado por diversos autores (Boelens, 2014; Fernandez, 2014; Hommes $\&$ Boelens, 2017), se refere às formas de legitimação da gestão e controle sobre a água por meio dos discursos, que muitas vezes apresentam argumentos que buscam naturalizar relações hidrossociais, promovendo padrões desiguais na distribuição de água, levando inclusive a exclusões de acesso (Boelens, 2014).

Esses discursos visam, muitas vezes, neutralizar e obscurecer os interesses políticos (Fernandez, 2014) que estão por trás das propostas ou conceituações defendidos por atores ou coalizões. Neste sentido, a compreensão sobre o que é a água (recurso, direito, bem comum), categorias de escalas, entre outros aspectos dos imaginários que são analisados nesta pesquisa, como apontam Hommes \& Boelens (2017), poderiam ser naturalizadas através de discursos de atores com diversos tipos de recursos e poder distintos (poder discursivo, político, econômico), organizados em alianças para "cimentar" esses imaginários na infraestrutura hidráulica.

Neste sentido, os territórios hidrossociais são construídos por meio de discursos e práticas que moldam as interações, alianças e lutas de poder em redes socionaturais espacialmente delimitadas (Hoogesteger et al., 2016). A partir do ponto vista de Boelens et al. (2016), o termo "hidrossocial" possui uma conotação de rede multiescalar limitada espacialmente, com escalas sobrepostas e contrapostas, hierarquicamente embebidas por elementos administrativos, jurídicos, culturais, organizacionais e hidrológicos.

Vale destacar que, para realizar esta análise multiescalar, é empregada a compreensão de escala geográfica, baseada na noção de que esta é socialmente produzida e é dependente da luta política (Delaney \& Leitner, 1997; Brown \& Purcell, 2005; Norman et al., 2012; Hoogesteger \& Verzij1, 2015). Howitt (1998) aponta que as escalas geográficas possuem diferentes dimensões. A partir desta conceituação, Hoogesteger et al. (2016) sintetizam a escala em: tamanho (extensão de um grupo social, lugar); nível (local, regional, nacional, global); relação ("laços" entre diferentes atores e espaços); e descrição do conteúdo (definição de qual é a escala e com o que ela lida). Cox (1998), avançando essa compreensão de escala enquanto relações, vai destacar que a escala é central nos discursos políticos e pode ser compreendida não somente como unidade de área, mas como redes de interação.

É a partir desta concepção de escala e da formulação de Swyngedouw (2004), em que a (re) construção de novas reconfigurações escalares é um meio para promover determinados interesses, que a análise da estratégia de reescalonamento estará embasada. Para isso, se adota a definição de Hoogesteger \& Verzijl (2015) e Hoogesteger et al. (2017), na qual novos arranjos escalares surgem das interações entre projetos políticos novos e os já existentes, reorganizando as relações entre as escalas e atuando de forma significativa sobre as relações de poder, autoridade e legitimidade de práticas em uma determinada escala (Hoogesteger et al., 2017).

Swyngedouw \& Boelens (2018) argumentam que, dentro desta concepção, as lutas pela justiça hídrica implicam em um esforço para remodelar e redesenhar as redes hidráulicas, unidades e elementos subjacentes à lógica e estrutura dos territórios hidrossociais dominantes. Para isso, portanto, as lutas envolvem uma necessidade de transformação de normas, relações políticas distributivas, tecnolo- 
gias, noções de eficiência técnica e a construção e envolvimento de novas redes de múltiplas escalas.

Neste artigo, a noção de justiça hídrica baseia-se nos desenvolvimentos conceituais Zwarteveen \& Boelens (2010; 2011). Neste sentido, a justiça hídrica não se refere somente à possibilidade de acesso à água, mas também ao direito de participação ou representação nos espaços decisórios e nas definições das regras que garantem esse acesso à água. Zwarteveen \& Boelens (2011) ressaltam que a compreensão das lutas e disputas travadas em torno dos direitos de propriedade ou de controle da água poderiam ser um primeiro passo para abordar a justiça hídrica. Posto isto, o entendimento sobre os imaginários e projetos hidrossociais, a forma de materializá-los, as modificações institucionais e burocráticas proporcionadas pela implementação destes, as consequências sobre quem acessa a água e como este acesso é feito, a determinação de quem participa dos processos decisórios e como esta participação ocorre, entre outros, possibilita também analisar a disputa entre diferentes noções de justiças hídricas.

Assim como Zwarteveen \& Boelens (2011), Swyngedouw \& Boelens (2018) também trabalham com a noção (ou noções) de justiça hídrica e exploram como esta é alterada ao longo do tempo e interage com diferentes visões políticas, imaginários socioculturais e configurações hidroterritoriais. Swyngedouw \& Boelens (2018) apontam ainda que, no processo de transformação dos territórios hidrossociais, as escalas e as formas como elas se conectam necessitam estar continuamente em reprodução e, em função disso, estão sujeitas a negociações, lutas e contestações.

A partir dos desenvolvimentos conceituais de Zwarteveen \& Boelens (2011) e Swyngedouw \&
Boelens (2018), é possível adotar a compreensão de múltiplas noções de justiças hídricas, que podem variar de acordo com as escalas e os interesses de seus atores, e analisar como podem ocorrer injustiças hídricas para atores da escala local. Essas injustiças decorrem da implementação de estratégias escalares para a materialização de imaginários, que podem ser invisíveis, imperceptíveis ou até mesmo aceitáveis a atores de outras escalas.

Por fim, Swyngedouw \& Boelens (2018) destacam que a possibilidade de as alianças dominantes ou opositoras serem bem-sucedidas em produzir, reforçar ou reordenar os territórios hidrossociais e os paradigmas de justiça hídrica, associados aos imaginários e projetos hidrossociais, dependerá de suas capacidades de rede, de mobilização e de exercício de poder.

É com base no referencial exposto que se formula a hipótese de que o processo de reescalonamento, a partir da construção de uma nova escala com a formação da Região Metropolitana, como será mais bem apresentado a seguir, possibilitaram ao Governo Estadual maior influência sobre as regras, direitos e estruturas organizacionais do setor de saneamento. Esse processo de reescalonamento, por sua vez, possibilita o (re)alinhamento das hierarquias de poder entre os atores (governamentais e não governamentais de diferentes escalas), de forma a produzir injustiças hídricas em escala local.

\section{O Estudo de caso - Coalizões multiníveis e multiescalares}

O conflito socioambiental deste estudo ocorre durante o período mais seco no ano (inverno), entre maio e agosto de 2012, no Município de Ilhabela, 
Litoral Norte do Estado de São Paulo. Esse período seco foi intensificado pela redução de chuvas em toda a região sudeste (ANA, 2015), e, com isso, a disponibilidade hídrica (física) se mostrou insuficiente para atender aos usos que se fazem dessa água na sub bacia localizada ao sul de Ilhabela. Para atender à demanda excedente, é realizada uma transposição de água entre duas microbacias, inseridas na sub bacia dos córregos Frade/ São Sebastião.

Essa transposição ocorre após a solicitação da outorga para captação de uso água da microbacia vizinha por parte de um condomínio de casas de veraneio ao Departamento de Águas e Energia do Estado de São Paulo (DAEE). O condomínio, segundo os atores locais entrevistados, teve então autorizada a outorga que possibilitou a captação superficial de água. Para a instalação do empreendimento cultural na mesma microbacia que o condomínio, foi estabelecido pelo DAEE, durante processo de licenciamento ambiental, que seria necessário o compartilhamento da vazão de água que já era captada pelo condomínio, como uma forma de não sobrecarregar a capacidade hídrica da microbacia de onde a água é transposta.

Na microbacia de onde é realizada a transposição de água, existe uma comunidade residente composta principalmente por uma população migrante que se mudou para Ilhabela em busca de emprego. É importante apontar que a comunidade residente na microbacia de onde a água é retirada não possui outorga de uso da água e sua ocupação, em sua maior parte, se encontra em processo de regularização fundiária (ABES, 2013; Tamoios News, 2018; Repórter Online Litoral, 2018; Radar Litoral, 2018; Ilhabela, 2018).

A partir do início da alteração do regime de chuvas, em 2012, com intensa redução de precipi- tação que perdurou pelos 3 anos seguintes (ANA, 2015), a disponibilidade hídrica do município foi alterada. Segundo relatado por entrevistados, o condomínio de casas de veraneio captou a mesma vazão outorgada ao longo de todo o ano, mesmo durante o período mais seco. Com a redução da disponibilidade hídrica, o volume de água captado pelo condomínio foi relativamente alto e provocou um desabastecimento da comunidade inserida na microbacia provedora.

Essa nova condição fez com que os atores locais (membros da associação de bairros local e da ONG que atua no Município), representando essa comunidade que ficou sem acesso à água, ao mesmo tempo em que buscaram discutir com o condomínio a possibilidade de redução da captação (ação que não obteve sucesso), se articularam a alguns atores do Comitê de Bacias Hidrográficas do Litoral Norte para a idealização e proposição de uma solução para o problema. Os atores do CBHLN, por sua vez, incluíram em 2013 a pauta para ser discutida no âmbito das reuniões da Câmara Técnica de Saneamento do $\mathrm{CBH}$ e formularam uma proposta de solução: um projeto-piloto de sistema alternativo de saneamento (com sistema de abastecimento de água) para atender a área do conflito, distribuindo água para os diversos usos dessa região do município (FalaCaragua, 2013; IIS, 2013; ABES, 2013; REBOB, 2014).

Começou a ser discutido um "Acordo de Cooperação do Projeto-Piloto", que tinha por objetivo estabelecer um vínculo de cooperação entre o CBHLN, a Prefeitura de Ilhabela, a Sabesp, o DAEE e a Associação Brasileira de Engenharia Sanitária e Ambiental de São Paulo (ABES/SP) a fim de viabilizar as atividades de planejamento, execução, gestão e acompanhamento do projeto-piloto do sistema de 
abastecimento de água e esgotamento sanitário na área do conflito (ABES, 2013).

Por envolver instituições locais/municipais e estaduais, a discussão saiu da escala local e da região do LN, passando para a escala estadual. Após informações coletadas em entrevistas com atores de diversas instituições, foi possível compreender que, em escala estadual, a partir de atores que atuam na sede em São Paulo, a SABESP alegou que a área foco do conflito constava em seu Plano de Ação e que seria, portanto, atendida por ela, e não caberia, assim, a execução de um projeto-piloto local com uso de recurso FEHIDRO.

Segundo dados levantados em uma entrevista realizada com um representante da associação de bairros, a SABESP apresentou a proposta de que o local seria atendido até 2016. No entanto, durante o período de 2014, o foco da opinião pública, dos órgãos estaduais e da SABESP se voltaram para a Região Metropolitana de São Paulo (RMSP), em função da "crise hídrica de São Paulo" (Jacob, 2014; Jacobi et al., 2015; Tadeu, 2016; Buckeridge \& Ribeiro, 2018), e o atendimento à região do LN foi novamente adiado em função das prioridades. Neste sentido, se percebe que a RMSP possui maior importância para os atores estaduais em uma relação hierárquica entre as regiões.

Em 2012, é formada a Região Metropolitana do Vale do Paraíba e Litoral Norte (RMVPLN ou RMVale), por meio da Lei Complementar $n^{\circ}$ 1.166/2012. Antes dessa Lei Complementar, segundo informações coletadas com atores locais, bem como a partir do levantamento de como se deu o processo de negociação entre a Prefeitura e a Sabesp, a tomada de decisão no que concerne aos investimentos em instalação ou ampliação das redes de abastecimento de água, bem como de coleta para posterior tratamento de esgoto, ocorria a partir de uma negociação entre o prefeito e a gerência da empresa concessionária dos serviços de saneamento. Com a instituição da RMVPLN é criado um "conselho de desenvolvimento" (São Paulo, 2012), que acaba por se tornar o espaço de deliberação sobre questões de interesse da região, tais como o caso do saneamento.

O estudo conduzido por Tadeu et al. (2018) identificou que os atores envolvidos no tema de acesso à água em Ilhabela estão articulados em três coalizões multiníveis, segundo a conceituação definida em Massardier et al. (2016). Tadeu et al. (2018) apontaram que a coalizão dominante, denominada "Técnico Administrativo", é composta por atores pertencentes às principais instituições estaduais envolvidas no conflito, tais como a Sabesp, DAEE e Secretaria Estadual de Recursos Hídricos.

Outra coalizão, identificada como "Político Tecnocrata", é formada principalmente por atores de instituições municipais ou estaduais, que possuem atuação técnica ou com interesses político-econômicos locais, tais como prefeitura de Ilhabela, Secretaria Municipal de Meio Ambiente, Sabesp de Ilhabela, condomínio de casas de veraneio e o empreendimento cultural. Por fim, a coalizão de oposição, denominada "Social Participativo", é composta por: atores locais pertencentes à ONGs que articularam outros níveis e tornaram o conflito visível; por membros do Comitê de Bacias Hidrográficas (CBHLN); e pelo Ministério Público. A configuração dessas coalizões está apresentada na Figura 1.

Deste estudo (Tadeu et al., 2018), é possível elencar características que possibilitam compreender 
os imaginários hidrossociais ${ }^{3}$ desses atores organizados em coalizões multiníveis ${ }^{4}$, tais como:

- Coalizão "Social Participativo" - os atores compartilham o valor da compreensão da água como um direito humano e apontam para a necessidade de ampliação da participação social. Esses atores se articulam para apresentar e defender a proposta de um sistema alternativo de solução ao problema - o projeto-piloto de tratamento e distribuição de água (descentralizado);

- Coalizão "Técnico Administrativo" - os atores compartilham o valor de que a água é fundamental para o desenvolvimento econômico e defendem que a inclusão de todos ao sistema de abastecimento deve ocorrer por meio de instrumentos das políticas (tarifas sociais e diferenciadas,

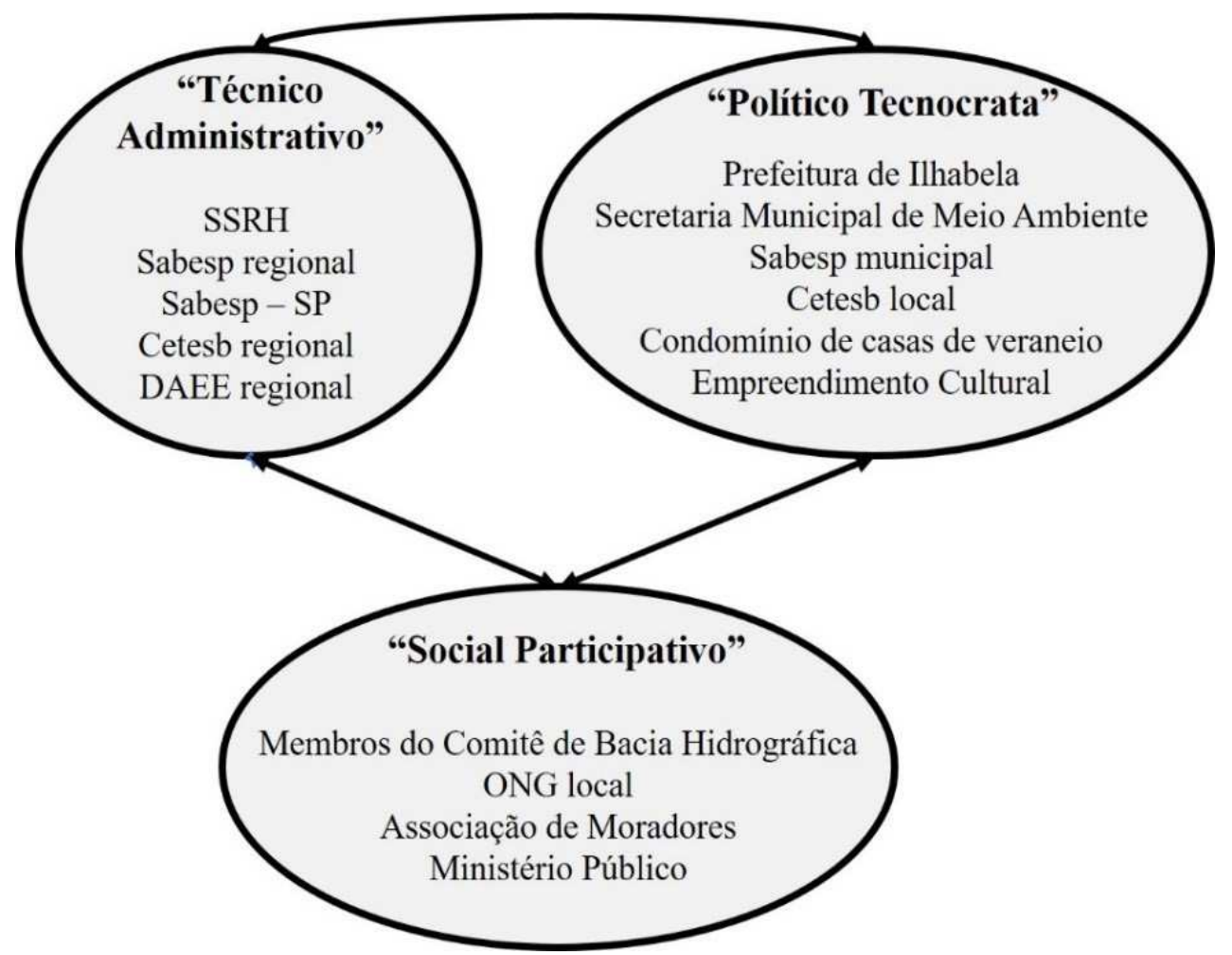

FIGURA 1 - Coalizões multiníveis do conflito pelo acesso à água em Ilhabela.

FONTE: Elaboração própria.

${ }^{3}$ Com base no trabalho de Hommes et al. (2016), neste artigo adota-se que os imaginários serão compostos pelos objetivos, valores, ideias e projetos hidrossociais pretendidos e imaginados pelos grupos ou coalizões.

${ }^{4}$ A nomenclatura das coalizões, proposta por Tadeu et al. (2018), se baseou em características gerais do grupo de atores. 
regularização fundiária, outorga de uso da água);

- Coalizão "Político Tecnocrata" - os atores compartilham o valor de que a água é fundamental para o desenvolvimento econômico e defendem que todos os usuários devem ser incluídos no sistema oficial da Sabesp para que possam ter acesso à água por meio do serviço de abastecimento.

Nos dados coletados para esta pesquisa, foi possível identificar que os atores das instituições que compõem essas coalizões, definidas por Tadeu et al. (2018), divergem em relação a suas percepções e posicionamentos em relação à formação da RMVPLN. Vale destacar que, principalmente entre os atores locais e os atores estaduais, foram observadas divergências significativas quanto a esse tema. Essas divergências são mais exploradas a seguir.

\section{A Região Metropolitana, o projeto de regionalização do Estado e as articulações entre as escalas}

A metropolização da região do Vale do Paraíba e do Litoral Norte, segundo Gomes et al. (2018), tratou-se de um projeto político administrativo, que só veio a incorporar o Litoral Norte de São Paulo em 2012. Os autores (Gomes et al., 2018) se baseiam no desenvolvimento teórico de Manoel L. Silva $\mathrm{Neto}^{5}$, que aponta que o processo de metropolização do espaço se trata de uma instrumentalidade para a sustentação da globalização econômica e tecnológica por meio da integração técnico-econômica do território, mediante a uma remodelação do território urbano regional.

Cabe destacar que as cadeiras do Conselho de Desenvolvimento da RMVPLN, ocupadas por instituições do Estado de São Paulo, são indicações feitas pelo governador, de acordo com a Lei Complementar $n^{0} 1.166 / 2012$. Ainda em 2012, por meio do Decreto $n^{0} 57.906$, de 23 de março de 2012, o Governo do Estado de São Paulo instituiu a Empresa Paulista de Planejamento Metropolitano (Emplasa) para realizar provisoriamente as funções de Secretaria Executiva do Conselho de Desenvolvimento da Região Metropolitana do Vale do Paraíba e Litoral Norte.

Gomes et al. (2018) ressaltaram que é necessário ter em conta que o governo estadual paulista visa reforçar uma proposta de integração da expansão metropolitana de São Paulo dentro de uma lógica neoliberal e com objetivo de expansão do mercado paulista, como um balizador da força de liderança política e ideológica do Estado de São Paulo, por meio da implementação do Plano da Macrometrópole Paulista. Os autores ressaltam ainda que a localização da RMVPLN parece ser estratégica para a promoção de tal expansão.

Neste sentido, é importante resgatar que, em 2011, foi criada a Secretaria de Desenvolvimento Metropolitano do Estado de São Paulo, que foi desativada dois anos depois, passando essa pasta para a Subsecretaria de Assuntos Metropolitanos (SAM), integrada à estrutura da Casa Civil do Estado de São Paulo (Castro \& Santos Junior, 2017; SAM, sd.).

${ }^{5}$ Silva Neto, M. L. A interação técnico-econômica do território paulista. In: Anais do II Encontro Brasileiro de Estudos Regionais e Urbanos. São Paulo, 20 de out., 2002. 
Ainda sob essa nova estrutura, a condução do tema segue de forma centralizada no Sistema Estadual de Desenvolvimento Metropolitano e da Câmara de Desenvolvimento Metropolitano, diretamente ligados ao poder executivo do governador (Castro \& Santos Junior, 2017).

Dentro desta perspectiva, observa-se que dentre as décadas de 1950 e 1980, a RMSP se tornou o epicentro da modernização, colocada em curso por meio das políticas de planejamento regional (Gomes et al., 2018). Nesse contexto é criada a RMVPLN, na qual a organização do território paulista passa a ter nas RMs, e, em um processo de metropolização ainda mais amplo, por meio da Macrometrópole Paulista $^{6}$, as principais unidades de planejamento, nas quais as propostas são negociadas e implementadas diretamente pelo governo estadual (Castro \& Santos Junior, 2017).

A integração da RMVPLN à RMSP, desta forma, se trata da expansão da região concentrada para além dos limites metropolitanos, colocando em passo uma nova etapa da produção do "espaço urbano-regional" do Vale do Paraíba e do Litoral Norte (Gomes et al., 2018).

Cabe ressaltar que a análise da Macrometrópole Paulista não integra o escopo desta pesquisa, contudo, estudos apontam que o reconhecimento e a institucionalização de novas regiões metropolitanas, tal como ocorreu com a RMVPLN, resulta deste projeto de planejamento territorial, ao qual a Macrometrópole faz parte (Castro \& Santos Junior, 2017; Gomes et al., 2018).

\section{A escala como estratégia de poder}

A partir da perspectiva fornecida pelo princípio da "criação de novas configurações escalares" (Hoogesteger \& Verzijl, 2015; Hoogesteger et al., 2017), é possível analisar a formação da RMVPLN pelo Governo Estadual. Com a articulação em torno da formação da RMVPLN, se observa uma sobreposição de escalas. Como buscamos levantar a partir dos estudos aqui revisados, esse processo de metropolização se insere em uma lógica de organização do território paulista em torno de uma proposta de integração da expansão metropolitana de São Paulo (Gomes et al., 2018), que passa a ter nas RMs e na Macrometrópole as principais unidades de planejamento, nas quais as propostas são negociadas e implementadas diretamente pelo governo estadual (Castro \& Santos Junior, 2017).

Segundo Tadeu et al. (2018), a composição do Conselho de Desenvolvimento da RMVPLN acaba por favorecer a ênfase dos interesses do governo do Estado de São Paulo. Alves (2018), por sua vez, aponta que esses interesses são reforçados pelo alinhamento das decisões do Conselho Estadual de Saneamento (CONESAN) ao plano de governo estadual vigente.

Posto isto, a inserção do LN na Região Metropolitana do Vale do Paraíba se mostra como um instrumento utilizado de formas distintas pelos diferentes atores. A partir de entrevistas com atores locais, foi possível identificar que não é consensual a percepção dos benefícios da inserção do LN na

\footnotetext{
${ }^{6}$ A Macrometrópole Paulista compreende uma região que se tornou o maior polo produtivo e de maior densidade urbana do país (DAEE, 2013), além de ser considerada um dos maiores aglomerados urbanos do Hemisfério Sul (Emplasa, 2017). Essa região foi definida a partir da consideração da dinâmica de desenvolvimento urbano e econômico das Regiões Metropolitanas (RM) de São Paulo, Campinas, Baixada Santista, Sorocaba, Ribeirão Preto, Vale do Paraíba e Litoral Norte e as aglomerações urbanas de Jundiaí e de Piracicaba (Emplasa, 2017).
} 
RMVPLN. Por um lado, alguns atores entrevistados apontaram que as decisões da prefeitura e dos demais municípios estariam limitadas, pois deveriam passar também pelas decisões do conselho de desenvolvimento da RMVPLN.

Um dos pontos levantados se refere à autonomia municipal. Isto porque, principalmente segundo os atores, que no estudo de Tadeu et al. (2018) estariam organizados na coalizão "Social Participativo", ao estabelecer um conselho deliberativo que conta com a participação de representantes dos Municípios (prefeitos) com os representantes do Estado, a autonomia do município é "diluída" e se incrementa a "centralização" da tomada de decisão, por permitir mais influência por parte dos atores do Estado. Além de o fato da região metropolitana ter sido definida pelo Governo do Estado de São Paulo, de forma a incluir a região do Litoral Norte a uma região que não apresenta as características de conurbação ou outras similaridades com os demais municípios do Vale do Paraíba.

Isto pode ser conferido em trechos extraídos de entrevistas realizadas com os atores direta e indiretamente envolvidos com o conflito pelo acesso à água. Um dos atores entrevistados relatou que:

“[...] esses contratos não foram assinados, a gente não sabe se serão, quando serão, porque se criou a região metropolitana que engloba o litoral norte, [...] O que a gente tá entendendo pelo que o próprio Estado tem falado pra gente através da Secretaria de Saneamento e Recursos Hídricos, é que quem vai assinar contrato não é mais cada Prefeito assina com a SABESP. Quem assina é a região.

[...] Então você imagina, vamos supor, a SABESP tem lá um investimento X pra região metropolitana. Nossa cidade tem 30.000 habitantes, que tem um prefeito que é um voto lá, quer dizer, como que vão ser priorizado? Aonde vai ter investimento? Será que não vai ser priorizados os municípios que tem mais gente? Entendeu? " (informação verbal')

Neste trecho, é possível notar a preocupação do ator entrevistado com o um entrave que havia sido criado na época da instituição da RMVPLN em relação à assinatura do contrato de programa e principalmente com a diluição do poder municipal de pressionar a SABESP em relação à cobrança de investimentos no município dentro do conselho deliberativo da RM. Outro ator local, classificado na coalizão "Social Participativo" por Tadeu et al. (2018), chegou reforçar que:

“[...] A região metropolitana criou uma agência que vai gerenciar os contratos com a SABESP.

[...] O governo quer que todos contratem a $S A$ BESP. [...]. E como que você faz isso? Como que você amarra um município? Não tem como, a não ser que se crie uma lambança dessa como essa região metropolitana" (informação verbal ${ }^{8}$ ).

Neste trecho, o ator discutia sobre a possibilidade de maior interferência da RMVPLN sobre a autonomia dos municípios na escolha das empresas à qual seria concessionado o serviço de saneamento, sobre o qual o município é o titular (Brasil, 2007). De acordo com as entrevistas realizadas, mesmo dentro da coalizão "Político Tecnocrata" (Tadeu et $a l, 2018)$, na qual a prefeitura e os órgãos municipais estão inseridos, não existe consenso quanto aos ganhos de Ilhabela integrar a RMVPLN. No momento

\footnotetext{
${ }^{7}$ Entrevista realizada no dia 30 de outubro de 2015.
}

${ }^{8}$ Entrevista realizada no dia 16 de novembro de 2015. 
que se realizaram as entrevistas, um dos atores que assumia uma posição estratégica em um dos órgãos municipais chegou a afirmar que:

“[...] as Prefeituras do Litoral Norte não têm nenhum contrato com a Sabesp. Ela faz o trabalho aqui no Litoral Norte, mas não tem contrato individualmente com cada município, inclusive está em discussão como fazer um contrato individual com o município na região metropolitana. Porque envolveram o Litoral Norte na Região Metropolitana do Vale do Paraíba, quer dizer, eu acho que nem caberia" (informação verbal $^{9}$ )

Neste trecho da entrevista, foi possível verificar que o ator não estava convencido sobre a coerência e os benefícios que a inserção na RM traria ao município e ao LN, principalmente no que tocava ao tema de contrato com a empresa de saneamento, uma vez que o setor de saneamento seria um tema a ser tratado em nível regional após a conformação da RM.

Desta forma, essa nova "correção escalar", criada com a instituição e implementação da RMVPLN para parte desses atores, acaba por ampliar o controle dos atores estaduais sobre a questão do saneamento básico. Por outro lado, essa mesma “correção escalar" é usada pelas prefeituras como uma forma de pressionar os atores estaduais, tendo em vista que o pertencimento do LN à uma região metropolitana poderia conferir maior atenção das políticas públicas de promoção do desenvolvimento.

O prefeito de Ilhabela em 2013, que estaria articulado na coalizão "Político Tecnocrata" segundo Tadeu et al. (2018), foi vice-presidente do conselho de desenvolvimento da RMVPLN, tendo sua chapa reeleita e em 2014 (CD-RMVPLN, 2013; 2014). No ano de 2015, foi eleito presidente desse conselho (CD-RMVPLN, 2015) e em seu primeiro pronunciamento, ele destacou que a união dos prefeitos como uma região seria importante para avanços em alguns setores das políticas pública: "São cada vez maiores as cobranças, bem como as dificuldades enfrentadas pelos municípios. Teremos saúde e segurança pública como as áreas prioritárias de atuação" (Ilhabela, 2015, p. 1). E quanto aos temas de saneamento e resíduos sólidos, ele ressaltou que: "A velocidade tem que ser cada vez maior em busca de soluções integradas. Temos de buscar junto ao Governo do Estado investimentos que são importantes para toda a região" (Ilhabela, 2015, p. 1). O prefeito foi indicado e reeleito para a presidência do conselho em 2016 (CD-RMVPLN, 2016).

Durante a reunião que elegeu a nova presidência e vice-presidência do conselho em 2018, a atual vice-prefeita de Ilhabela, representando o prefeito, afirmou que: "Essa eleição é de extrema importância para seguirmos com os trabalhos de desenvolvimento em toda RM Vale e Litoral Norte. Ilhabela sempre estará presente em assuntos que envolvam o crescimento sustentável do nosso município" (Noticiário Paulista, 2018, p. 1).

A partir dessas falas, é possível perceber que existe uma aposta municipal na inserção de Ilhabela na RMVPLN como uma forma de articulação regional, que possuiria maior força para angariar investimentos estaduais para os municípios. Em contraponto, Alves e Toledo (2018) reportam que desde 2016, a RMVPLN recebeu somente 30,5\% do orçamento previsto a ser investido pelo Governo do Estado.

${ }^{9}$ Entrevista realizada no dia 19 de janeiro de 2016. 
Posto isto, cabe ainda evidenciar que o evento que ficou conhecido como "crise hídrica de São Paulo”, com maior destaque em 2014 (Jacob, 2014; Jacobi et al., 2015; Tadeu, 2016; Buckeridge \& Ribeiro, 2018), salientou conflitos que antes eram latentes. No caso do Litoral Norte, isto se mostra de forma mais clara ao observar os posicionamentos dos distintos atores em relação aos investimentos que seriam destinados para os serviços de abastecimento e esgotamento sanitário do LN, que passam a se concentrar em obras de captação de água para a Região Metropolitana de São Paulo ${ }^{10}$. Com isso, percebe-se que ocorre uma disputa entre os níveis municipais e da região do Litoral Norte, com as RMVPLN e RMSP.

Como se buscou explorar até aqui, a análise multiescalar dos territórios hidrossociais possibilitou analisar como ocorrem as disputas entre projetos hidrossociais de atores que atuam em diferentes escalas. Isto pôde ser observado por meio da ação dos atores que atuam em escala local, que não concordam com os benefícios da criação da Região Metropolitana e que chegaram a articular uma proposta tecnológica de solução ao problema por meio do projeto-piloto no âmbito do Comitê de Bacias Hidrográficas do Litoral Norte como uma forma de reconhecimento e fortalecimento da escala da Região do Litoral Norte de São Paulo.

Sem embargo, essa alternativa foi descartada por atores da companhia estadual de saneamento que atuam em escala estadual e que manifestaram ser função da Sabesp o atendimento da região, por constar em seu Plano de Ação. A formação da RMVPLN atuou como um instrumento que reforçou o poder da Sabesp e dos atores governamentais que atuam em escala estadual sobre a escala local. Isso porque, como conceituado por Hoogesteger et al. (2017), novos arranjos escalares podem ser produzidos a partir da interação entre projetos novos e os já existentes.

Esse processo de reescalonamento, rearranja as relações entre as escalas (municipal, regional e estadual), reestabelecendo uma nova hierarquia de relações de poder, de autoridade e de legitimidade (Hoogesteger et al. 2017), uma vez que o tema de abastecimento de água, um dos componentes dos serviços de saneamento básico, seria de titularidade municipal (Brasil, 2007) e passa a ser um tema deliberado pelo Conselho de Desenvolvimento da Região Metropolitana (São Paulo, 2012).

Essa nova escala, por sua vez, também foi legitimada e naturalizada pela prefeitura de Ilhabela, que visualizou nesta uma oportunidade de ampliar os investimentos estaduais na região do Litoral Norte. Desta forma, esse processo de reescalonamento atuaria como um canal de pressão "de baixo para cima", no entanto, essa forma de atuação não foi observada, tendo em vista que os investimentos da RMVPLN previstos para o LN ainda não ocorreram (Alves \& Toledo, 2018).

Ademais, ao reorganizar hierarquicamente a relação de poder entre os atores locais (municipais), regionais e estaduais, também foi evidenciada a priorização da RMSP em relação à Região do Litoral Norte. Como se buscou apresentar e discutir, com o evento da "crise hídrica de São Paulo", a disputa entre os municípios da região do Litoral Norte com a RMSP, como regiões do Estado de São Paulo,

\footnotetext{
${ }^{10}$ Informações obtidas a partir das entrevistas com atores locais, notícias veiculadas no período (Lobel, 2015; Leite \& Akel, 2015; Arcoverde, 2016) e atas das reuniões do CBHLN (2016; 2017b).
} 
demonstrou que os atores estaduais priorizaram a RMSP por meio do direcionamento de recursos que deveriam ser investidos para atender à região e solucionar o problema que gera o conflito por acesso à água em Ilhabela.

Neste sentido, foi possível perceber como a sobreposição de escalas, produzida a partir da criação da RMVPLN, está inserida num contexto político, econômico, jurídico, administrativo e hidrológico hierárquicos em suas relações de poder. Neste contexto, as políticas territoriais associadas às escalas administrativas estadual, regional e municipal competem entre si e são articuladas como forma de fortalecer as reivindicações de controle sobre a água, como conceituado por Boelens (2014), Boelens et al. (2016) e Swyngedouw \& Boelens (2018). Desta forma, foi possível ainda perceber que estes territórios hidrossociais multiescalares estão interligados e se contestam entre si e é por meio dessas disputas escalares que os atores podem buscar materializar seus interesses de controle sobre a água, como pontuado por Hoogesteger et al. (2016).

Com base no desenvolvimento de Swyngedouw \& Boelens (2018), é possível ainda analisar que o projeto hidrossocial e a noção de justiça hídrica, que prevalece sobre o território local, priorizam outra região do Estado de São Paulo e acabam por manter as condições que originaram o conflito por acesso à água. Isto porque, não são consideradas ações que garantam uma política distributiva de água, e parte da população, com menor capacidade de custear equipamentos que garantam sua captação à montante de outros usos, não tem acesso à água em determinados períodos de menor disponibilidade hídrica (como ocorreu entre os anos de 2012 e 2015).

\section{Conclusões}

A perspectiva fornecida pela análise dos territórios hidrossociais possibilitou identificar as disputas entre distintos projetos e imaginários hidrossociais dos atores envolvidos direta e indiretamente no conflito, que possuem diferentes concepções de relação e modificação do fluxo hídrico natural e artificial (por meio dos serviços de saneamento). Neste âmbito, a análise realizada por Tadeu et al. (2018) pôde ser ampliada de forma a considerar a investigação das distintas formas de concepções da água pelos diferentes atores envolvidos e suas distintas visões, entendimentos e discursos para sustentar suas posições, bem como seus posicionamentos em relação à formação da RMVPLN dentro de uma estratégia mais ampla de materialização de imaginários hidrossociais (Hoogesteger \& Verzij1, 2015; Hoogesteger et al., 2016; Boelens et al., 2016; Swyngedouw \& Boelens, 2018).

Com isso, além de compreender como os atores se articulam em torno de um conflito por acesso à água, foi possível também visualizar como esses atores idealizam esses projetos hidrossociais e buscam, por meio de estratégias escalares, estabelecer e cimentar as relações hierárquicas que determinam quem participa do processo de tomada de decisão no setor de saneamento básico e como ocorre esta participação, que acaba por afetar diretamente quem terá acesso à água e como será feito esse acesso.

Vale mencionar que os grupos de atores buscam "naturalizar" de diferentes maneiras seus imaginários na infraestrutura hidráulica. A concepção da água como um recurso, em função de sua importância para a promoção do desenvolvimento econômico, seja este local/municipal ou regional/ 
estadual, é apresentada de forma naturalizada pelos atores atuantes em escala estadual, bem como aqueles relacionados às instituições governamentais municipais e ao setor econômico local, classificados nas coalizões "Técnico Administrativo" e "Político tecnocrata" por Tadeu et al. (2018).

A naturalização dessa concepção da água é relevante dentro da disputa entre escalas distintas, pois a água enquanto recurso para o desenvolvimento econômico possibilita a determinação de critérios empregados pelos atores que participam do processo de decisão que justifiquem a priorização de áreas enfocadas para a realização de maiores investimentos em infraestrutura de saneamento. Esses maiores investimentos acabam por alterar os fluxos hídricos, aumentando ou reduzindo a disponibilidade hídrica para todos os grupos sociais.

Neste sentido, foi possível verificar que no território hidrossocial local a disponibilidade hídrica (física) possui menor relevância do que os aspectos políticos e econômicos nos conflitos por água. Isto porque o conflito, aqui estudado, não ocorre em função da indisponibilidade hídrica, mas sim em função das relações de poder que estabelecem como é realizada a gestão e gerenciamento do abastecimento de água (serviços de saneamento) e do acesso à água. Na escala estadual, as estratégias para reorganizar a estrutura organizacional e administrativa por meio da conformação de RMs, com uma possível maior interferência sobre as decisões locais acerca do tema de saneamento, se mostraram fatores relevantes.

Para implementar seus projetos, ainda que os atores locais tenham buscado por determinado intervalo de tempo (durante o período mais crítico do conflito) se articularem com atores que atuam em outros níveis e escalas, as estratégias adotadas pelos atores estaduais, que reorganizaram institucionalmente a hierarquia entre os atores que participam dos processos decisórios, acabaram por reduzir o poder dos atores locais.

Neste caso, a luta por justiça hídrica local que buscava o acesso à água, tanto por meio das formas alternativas de distribuição (projeto-piloto) quanto por meio de um maior papel dos grupos sociais (através do fortalecimento dos espaços participativos), foi superada pelas estratégias de atores estaduais, por meio do processo de reescalonamento, que reorganizou institucionalmente as regras sobre o controle da água e saneamento. Com isso, a noção de justiça hídrica dominante, que determina a lógica de seleção dos locais prioritários para a cobertura dos serviços de saneamento, produz o quadro de injustiça hídrica local, tendo em vista que grupos sociais, como por exemplo, a comunidade residente na microbacia, de onde a água é transposta, são cerceados do acesso à água em períodos mais secos.

\section{Agradecimentos}

O presente trabalho foi realizado com apoio da Coordenação de Aperfeiçoamento de Pessoal de Nível Superior - Brasil (CAPES) - Código de Financiamento 001; e com apoio da Fundação de Amparo à Pesquisa do Estado de São Paulo (FAPESP) - Recursos concedidos dentro do acordo bilateral ANR/FAPESP 2013 - Processo: 2013/50537-0. Também agradecemos à equipe do projeto "BlueGrass - The struggles for 'blue gold': from grassroots mobilizations for water to the internationalization of environmental policies. A multilevel analysis". 


\section{Referências}

ABES. Associação Brasileira de Engenharia Sanitária e Ambiental. Projeto piloto para implantação de tecnologias alternativas em saneamento na comunidade de Rodamonte - Ilhabela - SP. In: Seminário Soluções Inovadoras de Tratamento e Reuso de Esgoto em Comunidades Isoladas-Aspectos Técnicos e Institucionais. Campinas, 20221 de junho de 2013.

Alves, E. M. Trajetórias das decisões sobre políticas públicas de esgotamento sanitário e as influências das coalizões de defesa: estudo de caso de Ubatuba-SP. Tese (Doutorado em Ciências Ambientais) - USP, 2018.

Alves, E. M.; Tadeu, N. D.; Fracanlanza, A. P.; Sinisgalli, P. A.; Jacobi, P. R. Fighting for equal infrastructures - Coalitions for the sanitation-sewage public policies in Ubatuba (São Paulo, Brazil). In: Poupeau, F.; Razafimahefa, L; Robert, J.; Mercier, D.; Massardier, G.; Jacobi, P. (Org.). Water Conflicts and Hydrocracy in the Americas. Coalitions, Networks, Policies. São Paulo: IEE-USP, p. 123-140, 2018.

Alves, X.; Toledo, C. RMVale recebe só 30\% da verba em dois anos e projetos patinam, 2018. Disponível em: $<\mathrm{http} / /$ www.ovale.com.br/_conteudo/2018/06/especial/43328-rmvale-recebe-so-30-da-verba-em-dois-anos-e-projetos-patinam.html>. Acesso em: set. 2018.

ANA - Agência Nacional de Águas (Brasil). Conjuntura dos recursos hidricos no Brasil: informe 2015, 2015. Disponível em: < http://www.snirh.gov.br/portal/snirh/ centrais-de-conteudos/conjuntura-dos-recursos-hidricos/ conjuntura_informe_2015.pdf>. Acesso em: jun. 2019.

Arcoverde, L. Investimentos em despoluição do Tietê caem $36 \%$ e mancha de poluição cresce, 2016. Disponível em: <https://noticias.uol.com.br/cotidiano/ultimas-noticias/2016/05/18/investimentos-em-despoluicao-do-tiete-caem-36-e-mancha-de-poluicao-cresce.htm $>$. Acesso em: mar. 2018.

Biernacki, P.; Waldorf, D. Snowball sampling: problems and techniques of chain referral sampling. Sociological Methods \& Research, 10(2), 141-163, 1981. doi: 10.1177/004912418101000205
Boelens, R. Cultural politics and the hydrosocial cycle: Water, power and identity in the Andean highlands. Geoforum, 57, 234-247, 2014. doi: 10.1016/j.geoforum.2013.02.008

Boelens, R.; Hoogesteger, J.; Swyngedouw, E.; Vos, J.; Wester, P. Hydrosocial territories: a political ecology perspective. Water International, 41(1), 1-14, 2016. doi: 10.1080/02508060.2016.1134898

Brasil. Lei $n^{\circ} 11.445$, de 5 de janeiro de 2007. Estabelece diretrizes nacionais para o saneamento básico; altera as Leis $n^{\circ}$ s 6.766, de 19 de dezembro de 1979, 8.036, de 11 de maio de 1990, 8.666, de 21 de junho de 1993, 8.987, de 13 de fevereiro de 1995; revoga a Lei $\mathrm{n}^{\circ} 6.528$, de 11 de maio de 1978; e dá outras providências. Brasília: DOU de 08/01/2007, retificado em 11/01/2007.

Brown, C. J.; Purcell, M. There's nothing inherent about scale: Political ecology, the local trap, and the politics of development in the Brazilian Amazon. Geoforum, 36(5), 607-624, 2005. doi: 10.1016/j.geoforum.2004.09.001

Buckeridge, M.; Ribeiro, W. C. (org.). Livro branco da água: crise hídrica na Região Metropolitana de São Paulo em 2013-2015: Origens, impactos e soluções. São Paulo: Instituto de Estudos Avançados, 2018.

Castro, H. R.; Santos Junior, W. R. A expansão da macrometrópole e a criação de novas RMs: um novo rumo para a metropolização institucional no estado de São Paulo? Cadernos Metrópole, 19(40), 703-720, 2017. doi: 10.1590/2236-9996.2017-4001

CBHLN. Comitê de Bacias Hidrográficas do Litoral Norte. Ata da $2^{a}$ reunião ordinária do CBH-LN em 2016 - 16 de dezembro de 2016, 2016. Disponível em: <http://www. sigrh.sp.gov.br/public/uploads/records//CBH-LN/12076/ ata-plenaria-16-12-2016.pdf>. Acesso em: jul. 2019.

CBHLN. Comitê de Bacias Hidrográficas do Litoral Norte. Relatório de Situação dos Recursos Hídricos do Litoral Norte de 2017 - com dados de 2016, 2017a. Disponível em: < http://www.sigrh.sp.gov.br/public/uploads/documents// CBH-LN/12454/rs2017final.pdf>. Acesso em: jul. 2019.

CBHLN. Comitê de Bacias Hidrográficas do Litoral Norte. Ata da I reunião extraordinária do CBH-LN em 2017, 19 de outubro - Caraguatatuba, 2017b. Disponível em: < http://www.sigrh.sp.gov.br/public/uploads/records//CBH- 
-LN/13797/ata_1-reuniao_extraordinaria_cbh-ln.pdf $>$. Acesso em: jul. 2019.

CBHLN. Relatório de Situação dos Recursos Hídricos do Litoral Norte de 2018 - com dados de 2017, 2018. Disponível em: $<$ http://www.sigrh.sp.gov.br/public/uploads/documents//CBH-LN/13809/relatorio_situacao_2018_ugrhi03. pdf>. Acesso em: jul. 2019.

CD-RMVPLN. Conselho de Desenvolvimento da Região Metropolitana do Vale do Paraíba e Litoral Norte. Ata da quarta reunião ordinária do Conselho de Desenvolvimento da Região Metropolitana do Vale do Paraíba e Litoral Norte, realizada em 7 de março de 2013, 2013. Disponível em: $<$ https://www.emplasa.sp.gov.br/RMVPLN/ConselhoDesenvolvimento/SecretariaExecutiva $>$. Acesso em: jul. 2019.

CD-RMVPLN. Conselho de Desenvolvimento da Região Metropolitana do Vale do Paraíba e Litoral Norte. Ata da oitava reunião ordinária do Conselho de Desenvolvimento da Região Metropolitana do Vale do Paraíba e Litoral Norte, realizada em 31 do mês de março de 2014, 2014. Disponível em: $<$ https://www.emplasa.sp.gov.br/RMVPLN/ ConselhoDesenvolvimento/SecretariaExecutiva $>$. Acesso em: jul. 2019.

CD-RMVPLN. Conselho de Desenvolvimento da Região Metropolitana do Vale do Paraíba e Litoral Norte. Ata da $11^{a}$ reunião ordinária do Conselho de Desenvolvimento da Região Metropolitana do Vale do Paraíba e Litoral Norte, realizada em 30 de março de 2015, 2015. Disponível em: $<$ https://www.emplasa.sp.gov.br/RMVPLN/ConselhoDesenvolvimento/SecretariaExecutiva $>$. Acesso em: jul. 2019.

CD-RMVPLN. Conselho de Desenvolvimento da Região Metropolitana do Vale do Paraíba e Litoral Norte. Ata da décima quarta reunião ordinária do Conselho de Desenvolvimento da Região Metropolitana do Vale do Paraíba e Litoral Norte, realizada em 29 de março de 2016, 2016. Disponível em: $<$ https://www.emplasa.sp.gov.br/RMVPLN/ ConselhoDesenvolvimento/SecretariaExecutiva $>$. Acesso em: jul. 2019.

Cetesb. Companhia Ambiental do Estado de São Paulo. Relatório de qualidade das praias no estado de São Paulo 2017, 2018. Disponível em: <https://cetesb.sp.gov.br/praias/ wp-content/uploads/sites/31/2018/06/Relat $\%$ C3\%B3rio-de-Qualidade-das-Paraias-Litor\%C3\%A2neas-do-Estado-
-de-S\%C3\%A3o-Paulo-2017.pdf>. Acesso em: jul. 2019. Cook, D. J., Mulrow, C. D.; Haynes, R. B. Systematic Reviews: Synthesis of Best Evidence for Clinical Decisions. Annals of Internal Medicine, 126, 376-380, 1997. doi: 10.7326/0003-4819-126-5-199703010-00006

Cox, K. R. Spaces of dependence, spaces of engagement and the politics of scale, or: looking for local politics. $P O-$ litical Geography, 17(1), 1-23, 1998. doi: 10.1016/S09626298(97)00048-6

DAEE - Departamento de Águas e Energia Elétrica do Estado de São Paulo. Plano Diretor de Aproveitamento de Recursos Hídricos para a Macrometrópole Paulista, no Estado de São Paulo - Sumário Executivo, 2013. Disponível em: $<$ http://www.daee.sp.gov.br/index.php?option=com_content\&view=article\&id=1112:plano-diretor-de-aproveitamen

Delaney, D.; Leitner, H. The political construction of scale. Political Geography 16(2), 93-97, 1997. doi: 10.1016/ S0962-6298(96)00045-5

Emplasa. Empresa Paulista de Planejamento Metropolitano. Macrometrópole Paulista. Base de dados de 2017, 2017. Disponível em: <https://www.emplasa.sp.gov.br/MMP>. Acesso em: set. 2018.

FalaCaragua. Câmara Técnica de Saneamento do CBH-LN define plano de trabalho para 2013, 2013. Disponível em: $<$ http://www.falacaragua.com.br/cidades/camara-tecnica-de-saneamento-do-cbh-ln-define-plano-de-trabalho-para-2013>. Acesso em: mar. 2017.

Fernandez, S. Much Ado About Minimum Flows... Unpacking indicators to reveal water politics. Geoforum, 57, 258-271, 2014. doi: 10.1016/j.geoforum.2013.04.017

Gomes, C.; Reschilian, P. R.; Uehara, A. Y. Perspectivas do planejamento regional do Vale do Paraíba e litoral norte: marcos históricos e a institucionalização da região metropolitana no Plano de Ação da Macrometrópole Paulista. Revista Brasileira de Gestão Urbana, 10(1), 154-171, 2018. doi: 10.1590/2175-3369.010.001.AO07

Haesbaert, R. O mito da desterritorialização: do "fim dos territórios" à multi- territorialidade. Rio de Janeiro: Bertrand Brasil, 2004.

Hommes, L.; Boelens, R. Urbanizing rural waters: Rural-ur- 
ban water transfers and the reconfiguration of hydrosocial territories in Lima. Political Geography, 57, 71-80, 2017. doi: 10.1016/j.polgeo.2016.12.002

Hommes, L.; Boelens, R.; Maat, H. Contested hydrosocial territories and disputed water governance: Struggles and competing claims over the Ilisu Dam development in southeastern Turkey. Geoforum, 71, 9-20, 2016. doi: 10.1016/j. geoforum.2016.02.015

Hoogesteger, J.; Boelens, R.; Baud, M. Territorial pluralism: water users' multi-scalar struggles against state ordering in Ecuador's highlands, Water International, 41(1), 91-106, 2016. doi: $10.1080 / 02508060.2016 .1130910$

Hoogesteger, J.; Tiaguaro-Rea, Y.; Rap, E.; Hidalgo, J. P. Scalar Politics in Sectoral Reforms: Negotiating the Implementation Of water Policies in Ecuador (1990-2008). World Development, 98, 300-309, 2017. doi: 10.1016/j. worlddev.2017.04.036

Hoogesteger, J.; Verzijl, A. Grassroots scalar politics: Insights from peasant water struggles in the Ecuadorian and Peruvian Andes. Geoforum, 62, 13-23, 2015. doi: 10.1016/j. geoforum.2015.03.013

Howitt, R. Scale as relation: musical metaphors of geographical scale. Area, 30, 49-58, 1998. doi: 10.1111/j.14754762.1998.tb00047.x

IIS. Instituto Ilhabela Sustentável. Audiência Pública sobre Saneamento, 2013. Disponível em: $<$ http://iis.org.br/farol-da-ilha/audiencia-publica-sobre-saneamento/>. Acesso em: mar. 2016.

Ilhabela. Prefeitura Municipal da Estância Balneária de Ilhabela. Conselho de Desenvolvimento da RMVale, 2015. Disponível em: <http://www.ilhabela.sp.gov.br/blog/ conselho-de-desenvolvimento-da-rmvale/>. Acesso em: mai. 2018.

Ilhabela. Prefeitura Municipal da Estância Balneária de Ilhabela. Prefeitura de Ilhabela segue trabalhando no maior projeto de Regularização Fundiária da história da cidade, 2018. Disponível em: https://www.ilhabela.sp.gov. $\mathrm{br} / \mathrm{blog} /$ prefeitura-de-ilhabela-segue-trabalhando-no-maior-projeto-de-regularizacao-fundiaria-da-historia-da-cidade/. Acesso em: set. 2018.
Jacob, A. Sistema Cantareira e a Crise da Água em São Paulo: A falta de transparência no acesso à informação. São Paulo: Artigo 19 Brasil, 2014. Disponível em: < https://artigo19.org/wp-content/uploads/2014/12/Relat\%c3\%b3rio-Sistema-Cantareira-e-a-Crise-da- $\%$ c3\%81 gua-em-S\%c3\%a3o-Paulo- $\%$ e2\%80\%93-a-falta-de-transpar\%c3\%aancia-no-acesso- $\%$ c3\%a0-informa $\%$ c3\%a7\%c3\%a3o. pdf $>$. Acesso em: jul. 2019.

Jacobi, P. R.; Cibim, J.; Leao, R. S. Crise hídrica na Macrometrópole Paulista e respostas da sociedade civil. Estudos Avançados, 29(84), 27-42, 2015. doi: 10.1590/S010340142015000200003

Leite, F; Akel, S. Sabesp vai investir 55\% menos em esgoto, 2015. Disponível em: <http://sao-paulo.estadao.com. br/noticias/geral,sabesp-vai-investir-55-menos-em-esgoto, $1661740>$. Acesso em: ago. 2018.

Lobel, F. Sabesp cortará mais da metade de seus investimentos em esgoto, 2015. Disponível em: <http://www1. folha.uol.com.br/cotidiano/2015/04/1611040-sabesp-vai-cortar-mais-da-metade-de-seus-investimentos-em-esgoto. shtml>. Acesso em: ago. 2018.

Massardier, G.; Poupeau, F.; Mayaux, P. L.; Mercier, D.; Robert, J.; Cortinas, J. Multi-Level Policy Coalitions an Interpretative Model of Water Conflicts in the Americas. Ambiente \& Sociedade, 19(4), 153-178, 2016. doi: 10.1590/1809-4422ex0001v1942016.

Norman, E. S.; Bakker, K.; Cook, C. Introduction to the Themed Section: Water Governance and the Politics of Scale. Water Alternatives, 5(1), 52-61, 2012. Disponível em: < http://www.water-alternatives.org/index.php/alldoc/ articles/vol5/v5issue1/157-a5-1-4/file>

Noticiário Paulista. Ilhabela participa de eleição do Conselho de Desenvolvimento da Região Metropolitana do Vale do Paraiba e Litoral Norte - Prefeitura Municipal de Ilhabela, 2018. Disponível em: <http://www.noticiariopaulista.com. br/2018/06/07/ilhabela-participa-de-eleicao-do-conselho-de-desenvolvimento-da-regiao-metropolitana-do-vale-do-paraiba-e-litoral-norte-prefeitura-municipal-de-ilhabela/ > . Acesso em: jul. 2019.

Poupeau, F.; Razafimahefa, L; Robert, J.; Mercier, D.; Massardier, G.; Jacobi, P. (Org.). Water Conflicts and Hy- 
drocracy in the Americas. Coalitions, Networks, Policies. São Paulo: IEE-USP, 2018.

Radar Litoral. Márcio Tenório anuncia obras de saneamento no Ilhote e ampliação de reservatórios de água, 2018. Disponível em: <http://radarlitoral.com.br/noticias/8897/ marcio-tenorio-anuncia-obras-de-saneamento-no-ilhote-e-ampliacao-de-reservatorios-de-agua $>$. Acesso em: set. 2018.

Raffestin, C. Por uma geografia do poder. São Paulo: editora Ática, 1993.

Rebob. Rede Brasil de Organismos de Bacias Hidrográficas. CBH-LN/SP aprova criação da Agência de Bacias do Litoral Norte, 2014. Disponível em: <http://www.rebob.org.br/ notcias/hxgzo5as119/CBHLNSP-aprova-cria $\% \mathrm{C} 3 \% \mathrm{~A} 7 \%$ C3\%A3o-da-Ag\%C3\%AAncia-de-Bacias-do-Litoral-Norte>. Acesso em: mar. 2016.

Repórter Online Litoral. Prefeitura de Ilhabela realiza audiência pública para apresentação do projeto final do Cantagalo, 2018. Disponível em: $<\mathrm{http}: / /$ www.reporteronlinelitoral.com.br/press/2018/04/05/prefeitura-de-ilhabela-realiza-audiencia-publica-para-apresentacao-do-projeto-final-do-cantagalo/>. Acesso em: set. 2018.

SAM - Subsecretaria de Assuntos Metropolitanos. Institucional - Sobre a Subsecretaria. Disponível em: <http:// www.assuntosmetropolitanos.sp.gov.br/Institucional/Sobre-a-Subsecretsria>. Acesso em: nov. 2018.

São Paulo. Lei Complementar $n^{\circ} 1.166$, de 09 de janeiro de 2012. Cria a região metropolitana do Vale do Paraíba e Litoral Norte, e dá providências correlatas. São Paulo: Diário Oficial do Estado, 2012.

Swyngedouw, E. Privatizando o H2O - Transformando Águas Locais em Dinheiro Global. Revista Brasileira de Estudos Urbanos e Regionais, 6(1), 33-53, 2004. doi: 10.22296/2317-1529.2004v6n1p33
Swyngedouw, E.; Boelens, R. “... And Not a Single Injustice Remains": Hydro-Territorial Colonization and Techno-Political Transformations in Spain. In: Boelens, R.; Perreault, T.; Vos, J. (Eds). Water Justice. Cambridge: Cambridge University Press, 2018, p. 115-133.

Tadeu, N. D. O sistema Cantareira e a crise da água em São Paulo: falta de transparência, um problema que persiste, 2016. Disponível em: <https://artigo19.org/wp-content/ blogs.dir/24/files/2016/06/Sistema-Cantareira-e-a-Crise-da-\%C3\%81 gua-em-S\%C3\%A3o-Paulo-2.pdf>. Acesso em: jul. 2019.

Tadeu, N. D.; Alves, E. M; Sinisgalli, P.; Fracalanza, A. P.; Jacobi, P. In the shadows of participation: Coalitions of water access in Ilhabela (São Paulo, Brazil) In: Poupeau, F.; Razafimahefa, L; Robert, J.; Mercier, D.; Massardier, G.; Jacobi, P. (Org.). Water Conflicts and Hydrocracy in the Americas. Coalitions, Networks, Policies. São Paulo: IEE-USP, p. 221-240, 2018.

Tamoios News. Projeto de Regularização Fundiária quer suprir déficit habitacional de Ilhabela, 2018. Disponível em: < https://www.tamoiosnews.com.br/noticias/cidades/ ilhabela/projeto-de-regularizacao-fundiaria-quer-suprir-deficit-habitacional-de-ilhabela/>. Acesso em: set. 2018.

Zwarteveen, M.; Boelens, R. Justicia Hídrica. Acumulación, Conflicto y Acción Social, 2010. Disponível em: <http:// www.wageningenur.nl/en/Publication-details.htm?publicationId=publication-way-343031323235>. Acesso em: jul. 2015.

Zwarteveen, M.; Boelens, R. La investigación interdisciplinaria referente a la temática de «justicia hídrica»: unas aproximaciones conceptuales. In: Boelens, R.; Cremers, L.; Zwarteveen, M. (Org.). Justicia hídrica: acumulación, conflicto y acción social. Lima: IEP; Fondo Editorial PUCP; Justicia Hídrica, p. 29-58, 2011. 